\title{
ESTIMATIVA DA FECUNDIDADE E INVESTIMENTO REPRODUTIVO DO CAMARÃO DE ÁGUA DOCE MACROBRACHIUM AMAZONICUM (HELLER, 1862) NO BAIXO RIO TIETÊ, UBARANA - SP
}

\author{
Costa, J.R.P. ${ }^{1,}{ }^{*}$; Carvalho, A.L.C. ${ }^{1}$; Rodrigues, L.R. ${ }^{\text {; }}$; Nunes, J.S. ${ }^{1}$; Brito, G.A. ${ }^{1}$; \\ Marques, S.C. ${ }^{1}$; Silva, M.A.G. ${ }^{1}$; Pantaleão, J.A.F. ${ }^{2} \&$ Andrade, L.S. ${ }^{1}$ \\ ${ }^{1}$ Universidade Federal do Triângulo Mineiro (UFTM), Campus Iturama, Grupo de Ensino, Pesquisa e Extensão em \\ Animais Aquáticos (GEPEAA). \\ ${ }^{2}$ Universidade Federal do Triângulo Mineiro (UFTM), Campus Uberaba (GEPEAA). \\ *Autor correspondente: jaquelinerobertaub@ hotmail.com
}

\begin{abstract}
Os aspectos reprodutivos como fecundidade e investimento energético alocado para a reprodução são os principais fatores para compreender a história natural de uma espécie ou de uma população. Assim, o objetivo deste estudo foi estimar a fecundidade e o investimento reprodutivo do camarão de água doce Macrobrachium amazonicum no Baixo Rio Tietê em Ubarana-SP. Os espécimes foram coletados mensalmente de novembro/2017 a maio/2018, com a utilização de peneiras e armadilhas do tipo puçá. Posteriormente, as fêmeas que portavam ovos foram individualizadas em álcool 70\% e mensuradas (comprimento da carapaça - CC) em laboratório. Com o auxílio de uma pipeta e pinça, os ovos aderidos aos pleópodos foram retirados. Foram selecionadas 41 fêmeas ovígeras com ovos em estágio inicial (excesso de vitelo, ausência de polo animal) para realização do estudo de investimento reprodutivo (IR). A massa de ovos foi retirada da fêmea e ambos foram submetidos a estufa por $60^{\circ} \mathrm{C}$, durante 24 horas. Em seguida, todo material foi pesado individualmente em balança semi analítica para obtenção da taxa reprodutiva (\%). Todos os ovos foram contados e comparados à dimensão corpórea (CC) da fêmea que os portava. Os resultados foram ajustados à uma regressão linear simples. Foram coletadas 177 fêmeas ovígeras, com tamanho médio de $13.48 \pm 1.86 \mathrm{~mm} \mathrm{CC}$, apresentando variação de 278 a 2444 ovos. A fecundidade média obtida foi de $1134.9 \pm 462.86$. As fêmeas com ovos em estágio inicial obtiveram média de 985,2 $\pm 406,9$. Os resultados de regressão linear simples indicaram uma relação significativa entre o comprimento da carapaça e a quantidade de ovos $\left(p<0.0001 ; r^{2}=0.69\right)$, deixando evidente que quanto maior for a fêmea, maior será a quantidade de ovos produzidos. Entretanto, este parâmetro pode sofrer influência de muitos fatores ambientais, como temperatura, latitude, disponibilidade de alimento e também do tamanho dos ovos produzidos. O investimento reprodutivo médio (razão entre peso seco da massa de ovos e peso seco da fêmea) foi de $0.147 \pm 0.140$. A relação entre tamanho da fêmea e IR também foi estatisticamente significativo $\left(p<0.0001 ; r^{2}=0.27\right)$, indicando maior alocação em energia para reprodução à medida que aumenta em tamanho (CC). A baixa alocação em energia para eventos reprodutivos em algumas fêmeas pode ser explicada pela reprodução contínua da espécie no local, observando que todos os meses obtiveram fêmeas em período reprodutivo.
\end{abstract}

Palavras-chave: camarão-da-amazônia, Caridea, Decapoda, reprodução. 